\title{
AVALIAÇÃO DE DESEMPENHO: UM ESTUDO DE CASO EM UMA COOPERATIVA DE CRÉDITO
}

\author{
MOREIRA, Andreia Aparecida Silva ${ }^{1}$
}

MOREIRA, Andreia Aparecida Silva. Avaliação de desempenho: um estudo de caso em uma cooperativa de crédito. Revista Científica Multidisciplinar Núcleo do Conhecimento. Ano 03, Ed. 09, Vol. 2, pp. 54-69, Setembro de 2018. ISSN:2448-0959

\section{RESUMO}

A avaliação de desempenho é um tema bastante importante da gestão de pessoas. Ela permite conhecer as ferramentas utilizadas pela empresa e como são aplicadas, analisando a eficácia e a motivação das mesmas para os funcionários, aprofundando os conhecimentos sobre o desempenho do funcionário. O estudo tem, como objetivo, identificar, compreender, analisar e discutir as ferramentas de desempenho e sua aplicação nos colaboradores da Cooperativa de Crédito, confrontando-as com as recomendadas pela literatura existente sobre o tema. Consiste em um estudo de caso, possuindo um caráter quantitativo e qualitativo. São analisados os resultados de um questionário aplicado a $40 \%$ do quadro de funcionários da empresa, oito estagiários e quatro menores aprendizes além do gestor do $\mathrm{RH}$. Os resultados indicam que a avaliação de desempenho na Cooperativa de Crédito ainda é falha e precisa de melhorias.

Palavras chave: Avaliação de desempenho, Cooperativa de Crédito, Pessoas.

\section{INTRODUÇÃO}

A avaliação de desempenho é um dos temas que mais absorve profissionais da área de Recursos Humanos nas organizações, buscando conhecer e medir o desempenho

1 Graduação em Administração; Pós-Graduação em Controladoria e Finanças Empresariais; Mestre em Administração. 
dos funcionários na empresa, estabelecendo uma comparação entre o desempenho esperado e o apresentado pelos funcionários.

Primeiramente os funcionários se auto avaliam e, após, os gestores de cada setor chamam o funcionário individualmente para que possa mostrá-los o resultados de seu desempenho na empresa. Com a avaliação em mãos, analisam todos os itens e apõem a porcentagem.

Com isso, o funcionário percebe em qual nível se enquadra, assina e data o papel concordando; em seguida, é repassada para o diretor responsável pela área verificar e assinar.

Portanto, com esse método de avaliação os gestores podem analisar o desempenho de cada funcionário dessa forma motivando-os à promoção de carreira dentro da empresa.

Assim, realizou-se um estudo de caso em uma Cooperativa de Crédito constituída em 13/07/1998 na cidade Cláudio Minas Gerais. Desde 2010, foi autorizada pelo Banco Central e tornou-se de livre admissão, ou seja, todas as pessoas físicas e jurídicas podiam se tornar cooperados. Sua principal finalidade é apoiar os seus cooperados, através de taxas acessíveis, e contribuindo para o desenvolvimento sociocultural e econômico da cidade e região. Possui 104 funcionários, 8 estagiários e 4 menores aprendizes que trabalham em função de 16.174 associados. Sua função se dá através da Assembleia Geral, órgão supremo da cooperativa do Conselho de Administração, Diretoria Executiva e Conselho Fiscal.

Diante do exposto acima tem-se o seguinte questionamento: Quais são as ferramentas utilizadas para avaliar o desempenho dos funcionários de uma Cooperativa de Crédito e como ela é aplicada?

Para responder ao questionamento levantado, foram estabelecidas algumas hipóteses, que guiarão o estudo: 
1. Acredita-se que não haja treinamento para as lideranças e colaboradores da Cooperativa de Crédito fazendo com que a avaliação de desempenho não gere resultados positivos.

2. As ferramentas de avaliação podem conter falhas e não estarem de acordo com os objetivos da Cooperativa de Crédito.

3. A forma de avaliar não está de acordo com os padrões da Cooperativa de Crédito e os responsáveis pela avaliação podem não ser as pessoas mais indicadas e preparadas.

É objetivo geral do estudo identificar, compreender, analisar e discutir as ferramentas de avaliação de desempenho e sua aplicação nos colaboradores da Cooperativa de Crédito. E, de modo específico, busca-se: a) Estudar os fundamentos teóricos sobre avaliação de desempenho e associá-los a realidade da Cooperativa de Crédito em estudo; b) Analisar os resultados da Avaliação de Desempenho, como base para propor melhorias de procedimento e, c) Analisar como ocorre os acompanhamentos após o feedback das avaliações.

O estudo é de extrema importância, pois conhecer as ferramentas utilizadas pela empresa e como são aplicadas, permite analisar se as mesmas são eficazes e motivam os funcionários. Permite também aprofundar os conhecimentos sobre 0 desempenho do funcionário, conteúdo valioso da disciplina de Gestão de Pessoas, além de ser uma importante ferramenta para o aprendizado acadêmico relacionando teoria e prática.

Esse artigo possui a seguinte estruturação: introdução que contém o problema, as hipóteses, os objetivos, a justificativa e a estrutura do artigo. Em seguida, é feita a revisão teórica, expondo conceitos e definições de avaliação de desempenho, seus objetivos, métodos, dentre outros itens, referenciando vários estudiosos, principalmente Chiavenato (1998 e 2014).

Após o referencial teórico, apresenta-se a interpretação dos dados obtidos junto a $40 \%$ dos funcionários da empresa, sendo 42 funcionários, 8 estagiários e 4 menores 
aprendizes, além do Gestor de Recursos Humanos. Encerrando apresentam-se as referências bibliográficas que serviram de suporte teórico para o seu desenvolvimento, e por fim, os anexos citados no decorrer do trabalho.

\section{REFERENCIAL TEÓRICO}

a avalição de desempenho permite conhecer o comportamento e a performance dos funcionários a partir de formulários e indicadores. dando subsídio aos gestores para acompanhar o desenvolvimento individual e em equipe. proporcionando a organização ter colaboradores eficientes, treinados, motivados desta forma gerando mais resultados. (chiavenato 1998).

\subsection{AVALIAÇÃO DE DESEMPENHO}

Chiavenato (1998) oferece uma importante contribuição ao descrever o histórico da avaliação de desempenho dizendo que as organizações não davam importância em avaliar o ser humano e sim a eficiência da máquina como forma de aumentar a performance da produtividade da empresa. Acreditava-se que o colaborador era motivado apenas por salários e benefícios.

Ainda segundo Chiavenato (1998), com o tempo, as organizações se deram conta que a máquina não resolvia o problema do desempenho e, com a origem da Escola da Abordagem Humanista da teoria da administração, passou-se a dar valor ao homem e rever maneiras de avaliá-lo de forma a trazer resultados significativos para a empresa e o colaborador.

Após a segunda guerra mundial, as avaliações de desempenho foram efetivamente difundidas nas organizações. (MOTTA apud CHIAVENATO, 1998).

\subsubsection{CONCEITOS}

A avaliação de desempenho mede o potencial de desenvolvimento do colaborador, proporcionando verificar os pontos fortes e pontos de melhoria, possibilidades de 
treinamentos, acompanhamento além de servir como base para cargos e salários, promoções entre outros. (CHIAVENATO 1998).

Segundo Chiavenato (2014, p. 209),

A avaliação é uma apreciação sistemática do desempenho de cada pessoa - ou de uma equipe - em função das atividades que desenvolve, das metas e resultados a serem alcançados, das competências que oferece e do potencial de desenvolvimento. A avaliação de desempenho é um processo que serve para julgar ou estimar o valor, a excelência e as competências de uma pessoa ou equipe e, sobretudo, qual é a sua contribuição para o negócio da organização. (CHIAVENATO, 2014, P. 209).

Através desse conceitos é possível perceber que a avaliação de desempenho é importante não só para a empresa mas para o próprio profissional ao ter seu potencial avaliado e analisar como melhorar os seus pontos positivos, levando a empresa a melhorar a sua performance tanto no mercado como na sua administração, "colaborando na determinação e no desenvolvimento de uma política adequada de RH às necessidades da organização" (CHIAVENATO, 2002, p. 326).

\subsubsection{OBJETIVOS DA AVALIAÇÃO DE DESEMPENHO}

Davis (1992) aponta que os objetivos da avaliação de desempenho são: proporcionar a igualdade de oportunidade aos colaboradores, dar retorno sobre o desempenho, propiciar crescimento, motivar, fazer com os colaboradores se comprometam com a empresa.

A avaliação de desempenho, segundo Pontes (1999), são cinco: planejamento da avaliação, objetivos da empresa e do colaborador, formulário de avaliação, acompanhamento de resultados e avaliação final.

Para Camilo (2016), são objetivos da avaliação de desempenho: 
Identificar pontos de melhoria das pessoas; Integrar os colaboradores à empresa, buscando adequar suas competências com as necessidades da empresas; Adequar as pessoas aos cargos que possuem ou que deveriam possuir; Identificar necessidade de treinamento e estabelecer meios e programas para reduzir essa carência. Melhorar a qualidade do trabalho e da vida dentro da empresa (CAMILO, 2016, p. 1).

Os objetivos, como se pode explanar, são claros e bem definidos e as empresas têm condições de oferecer oportunidades de crescimento e participação tanto à empresa como aos seus membros tanto do ponto de vista organizacional como do ponto de vista individual.

\subsubsection{PRINCIPAIS MÉTODOS DE AVALIAÇÃO DE DESEMPENHO}

Os métodos utilizados para avaliar o desempenho do colaborador são: escolha forçada, escala gráfica, pesquisa de campo e incidentes críticos. (CHIAVENATO, 2002; CHIAVENATO, 2014).

a) Escolha forçada: avalia individualmente o desempenho das pessoas, usando frases descritivas atentando a determinados comportamentos (CHIAVENATO, 2002; CHIAVENATO, 2014).

b) Escala gráfica: avalia o desempenho através de fatores já definidos, usando um formulário de dupla entrada (CHIAVENATO, 2002; CHIAVENATO, 2014).

c) Pesquisa de campo: é baseado em entrevistas contando com a participação de um especialista (GIL, 2001). "O especialista vai a cada seção para entrevistar as chefias sobre o desempenho de seus subordinados" (CHIAVENATO, 2002, p. 342).

d) Incidentes críticos: avalia as características extremas do comportamento humano que levam a resultados positivos ou negativos (CHIAVENATO, 2002; CHIAVENATO, 2014). 
Cada um deles, possui vantagens e desvantagens. A entrevista, em todos os métodos, é o principal ponto do sistema.

Existem três tipos de avaliação de desempenho, segundo Chiavenato (1998): 360 (superior avalia subordinado, subordinado se avalia e colegas se avaliam, ou seja, há interação entre todos os envolvidos); 180 (superior avalia subordinado, subordinado se avalia, traduzindo-se em uma rica troca, com transparência e objetividade) e 90ำ (superior avalia subordinado, o que pode provocar distorções de percepção).

A decisão de qual a melhor forma de avaliar as pessoas é feita pela diretoria da organização. (CHIAVENATO, 1998).

\subsubsection{RESPONSABILIDADE PELA AVALIAÇÃO DE DESEMPENHO}

De acordo com Chiavenato (1998) os responsáveis pela avaliação de desempenho são os gerentes, o colaborador, gerente e colaborador, a equipe de trabalho, o setor de recursos humanos e uma comissão de avaliação.

Os gerentes, segundo Chiavenato (2002), são apoiados pela assessoria da área de gestão de pessoas que instituem os critérios da avaliação.

O colaborador se auto avalia em relação "à sua performance, eficiência e eficácia" (CHIAVENATO, 2002, p. 326).

O gerente e o colaborador, juntos, realizam a avaliação de desempenho. O gerente, segundo Chiavenato (2002), guia e orienta e o colaborador avalia o seu desempenho baseado na retroação fornecida pelo gerente.

A equipe de trabalho, segundo Chiavenato (2002), avalia o desempenho próprio como um todo com o objetivo de providenciar as melhorias necessárias.

Segundo Chiavenato (2002), o setor de recursos humanos é responsável pela avaliação de desempenho de todas as pessoas da organização. 
A comissão de avaliação é escolhida pela própria organização; é formada por pessoas de órgãos diversos, que participam de todas as avaliações para manter o equilíbrio dos julgamentos (CHIAVENATO, 2002).

A avaliação do desempenho, pelo exposto, possibilita, aos gestores e às organizações, a medição e a análise da performance de cada funcionário, motivandoos à promoção de carreira dentro da empresa.

\subsection{COOPERATIVAS DE CRÉDITO}

De acordo com Pinheiro (2008), o Cooperativismo surgiu em 1844 na cidade de Rochdale, quando 28 tecelões fundaram uma cooperativa de consumo.

A primeira cooperativa de crédito não demoraria a surgir. Três anos depois, em 1847, Friedrich Wilhelm Raiffeisen, natural da Renânia, criou no povoado de Weyerbusch/Westerwald a primeira associação de apoio para a população rural, que, embora não fosse ainda uma cooperativa, serviria de modelo para a futura atividade cooperativista de Raiffeisen. A primeira cooperativa, fundada por ele em 1864, chamava-se "Heddesdorfer Darlehnskassenveirein" (Associação de Caixas de Empréstimo de Heddesdorf). As cooperativas criadas por Raiffeisen, tipicamente rurais, tinham como principais características a responsabilidade ilimitada e solidária dos associados, a singularidade de votos dos sócios, independentemente do número de quotas-parte, a área de atuação restrita, a ausência de capital social e a não-distribuição de sobras, excedentes ou dividendos. Ainda hoje, esse tipo de cooperativa é bastante popular na Alemanha. (PINHEIRO 2008, pág. 21).

Segundo Pinheiro (2008) as Cooperativas classificam-se em: singulares, quando prestam serviços diretamente aos clientes; cooperativas centrais e federações de cooperativas, constituídas por cooperativas singulares e que objetivam organizar, em comum e em maior escala, os serviços econômicos e assistenciais de interesse das 
filiadas e confederações de cooperativas, constituídas por centrais e federações de cooperativas e que têm por objetivo orientar e coordenar as atividades das filiadas.

As cooperativas de crédito têm crescido significativamente nos últimos anos, implicando na necessidade de soluções mais eficientes e eficazes para os problemas de gestão de seus recursos, visto que algumas delas não têm mais porte de pequena empresa familiar, mas de grande empresa com diversos interessados nos seus resultados: os cooperados. Com isso, a avaliação do desempenho se torna essencial para o crescimento contínuo desse tipo de entidade, podendo contribuir para o aprimoramento da estratégia definida e, consequentemente, garantir vantagens competitivas. (MARTINS, GIRÃO; SILVA E FILHO; ARAÚJO 2013, pág. 3).

As Cooperativas, segundo Pinheiro (2008), apesar de ocupar um pequeno espaço no sistema financeiro nacional, apresentam um constante crescimento em volume e participação na área bancária.

\section{METODOLOGIA}

Para atingir os objetivos propostos e responder o problema escolhido: "Quais são as ferramentas utilizadas para avaliar o desempenho dos funcionários da Cooperativa de Crédito e como é aplicada?" foi realizado um estudo de caso uma vez que esta técnica adapta perfeitamente ao perfil.

Nas ciências, durante muito tempo, o estudo de caso foi encarado como procedimento pouco rigoroso, que serviria apenas para estudos de maneira exploratória. Hoje, porém, é encarado como o delineamento mais adequado para a investigação de um fenômeno contemporâneo dentro de seu contexto real, onde os limites entre o fenômeno e o contexto não são claramente percebidos. (YIN, 2001 apud GIL, 2002, p. $54)$. 
Segundo Pereira (1999a), pode assumir diversos significados, em função do sentido conferido ao termo avaliação e do contexto relativo ao desempenho, motivo desta avaliação. Dessa forma, desempenho, no âmbito empresarial, atribui várias dimensões quando pertinente à empresa em sua plenitude, funcionalidade e atividades exercidas, bem como, os aspectos operacionais, econômicos e financeiros dos serviços planejados e realizados atingindo um processo de gestão como recurso nas tomadas de decisões.

O mesmo autor refere-se à avaliação como ato ou efeito de atribuir valor, podendo ser entendido como qualitativo (mérito, importância) ou quantitativo (mensuração).

Foram descritos dados e informações com observação do ambiente de trabalho e análise de documentos, sendo os mesmos examinados com o suporte do referencial teórico que, segundo Vergara (2000, p. 35), "é uma revisão da literatura existente, no que concerne não só ao acervo de teorias e suas críticas, como também os trabalhos realizados que as tomam como referência". Por isso, foram pesquisados livros sobre o assunto, além de teses e dissertações da internet.

A pesquisa caracterizou-se como quantitativa e qualitativa. Quantitativa, no sentido de interpretar e levantar conclusões, mostrando tabelas de percentuais e gráficos. E qualitativa, pois as informações colhidas foram analisadas de acordo com o roteiro aplicado e registradas em relatório, destacando opiniões, comentários e frases mais relevantes que surgiram.

O universo da pesquisa constituiu-se em uma Cooperativa de Crédito. A amostra foi representada por $40 \%$ do quadro de funcionários da empresa, 8 estagiários e 4 menores aprendizes. Além do Gestor de Recursos Humanos.

A pesquisa também foi descritiva, pois mostrou atributos da população em estudo; os dados coletados possibilitaram descrever como é feita a avaliação de desempenho da Cooperativa e quais as ferramentas são utilizadas. 
Os dados foram obtidos através de questionário com questões abertas e fechadas, o que proporcionou uma maior interação com os entrevistados podendo desta forma, atingir os objetivos da pesquisa.

Ao final, foram realizadas a tabulação e análise dos dados de forma a atingir os objetivos deste trabalho.

\section{RESULTADOS E DISCUSSÃO}

Quarenta por cento (40\%) dos funcionários, 8 estagiários e 4 menores aprendizes da Cooperativa de Crédito em estudo responderam o questionário. Além do Gestor de Recursos Humanos.

\subsection{QUESTIONÁRIO APLICADO AOS FUNCIONÁRIOS, ESTAGIÁRIOS E MENORES APRENDIZES}

Quanto ao perfil dos entrevistados, foram obtidos os seguintes resultados:

Quanto ao sexo: $70 \%$ dos entrevistados são do sexo feminino e $30 \%$ do sexo masculino.

Em relação a faixa etária, os funcionários, em sua maioria são jovens, pois $45 \%$ possui entre 19 a 23 anos de idade; $25 \%$ possui entre 24 a 28 anos de idade; $10 \%$ possui entre 29 a 33 anos de idade e $5 \%$ possui até 18 anos, totalizando $85 \%$ de pessoas jovens trabalhando na Cooperativa de Crédito. E 15\% na faixa etária entre 49 a 53 anos.

É uma geração nova e, a maioria já nasceu inserida em um mundo globalizado, conectados e usam os novos recursos tecnológicos como facilitadores da vida moderna. No relacionamento com clientes e na avaliação de desempenho, a idade pode ser uma fator de crescimento e de desenvolvimento dentro da empresa, sem desconsiderar os mais maduros. A vontade do jovem dentro da empresa, permite a sua evolução cognitiva e laboral. 
Em relação ao grau de escolaridade, o resultado mostra que enquanto $30 \%$ dos funcionários já possuem o 3ำ grau completo, $45 \%$ estão estudando, buscando novos conhecimentos e $5 \%$ já possui Pós Graduação. Este percentual totaliza $80 \%$ dos funcionários, enquanto $20 \%$ possuem o $2^{\circ}$ grau completo. Pode-se compreender este número elevado pela possibilidade de melhores salários e cargos.

A gestão do conhecimento é uma estratégia que transforma bens intelectuais da organização em maior produtividade, novos valores e aumento de competitividade.

Depois de levantado o perfil dos funcionários, foi-lhes aplicado um questionário com seis questões abertas, focalizando a eficácia da avaliação do desempenho, seus resultados, avaliação da liderança e das ferramentas de avaliação de desempenho utilizadas pela Gestão de Pessoas da sua empresa, identificação de pontos fortes e fracos da Cooperativa de Crédito e motivação ao receber feedback da liderança imediata.

Sobre a avaliação de desempenho, o resultado exibe que $50 \%$ dos funcionários expuseram que a avaliação é uma ótima ferramenta para medir o desempenho, pois através dela pode-se fazer uma análise e revisar a forma como estão agindo e, dessa forma, melhorar o desempenho na função exercida. Vinte e cinco por cento (25\%) disseram que a avaliação não proporciona muitos resultados, uma vez que há falhas na aplicação e na forma como é passada para o funcionário e, $25 \%$ proferiram que a avaliação não é eficaz já que não traz resultados práticos e o plano de desenvolvimento individual não é coerente e muitas não são monitoradas de forma correta.

Indagados se o resultado da avaliação de desempenho é positivo ou negativo, o resultado mostra que $60 \%$ disseram que é positivo, uma vez que conseguem absolver os itens que são passados e colocá-los em prática, mesmo o PDI sendo falho; $30 \%$ disseram que o resultado é negativo, pois a gestão de pessoas não consegue aplicar de forma correta a ferramenta e muitos gestores têm dúvidas na hora de passar o resultado. Os mesmos conseguem trabalhar suas falhas. Apenas 10\% disseram que o resultado em alguns aspectos é positivo e em outros negativos. 
Quando foi perguntado se a liderança sabe passar corretamente a avaliação de desempenho, 70\% disseram que sim. Afirmaram que, apesar das falhas nos resultados, eles sabem conversar e chegar a um acordo durante as sessões de feedback. Dão liberdade de expressar e questionar os pontos avaliados. Apenas 30\% relatam que não a liderança ainda precisa ser trabalhada com treinamentos e conhecimentos das ferramentas de avaliação, causando muitas falhas no resultado.

Com relação à avaliação das ferramentas utilizadas pela Cooperativa para medir o desempenho dos funcionários, $45 \%$ disseram que a avaliação de desempenho é uma excelente ferramenta utilizada pela área de gestão de pessoas. As competências avaliadas estão em acordo com a função que cada funcionário desempenha e, através dela, nota-se melhoria no desempenho por parte de todos os funcionários. Cinquenta e cinco por cento (55\%) dos funcionários responderam que as ferramentas são falhas e precisam de treinamentos para os gestores aplicarem de forma correta e, por consequência, gerar mais resultados.

As respostas dadas por $45 \%$ dos respondentes estão de acordo com o pensamento de Chiavenato (2002) em relação à avaliação de desempenho. Mas a maioria, 55\% ainda consideram a avaliação de desempenho falha e necessitando treinamentos para os gestores, o que é uma boa sugestão. Percebe-se que o resultado da avaliação de desempenho é considerado negativo.

Perguntou-se sobre a identificação de pontos fortes e fracos da avaliação de desempenho. O QUADRO 1 mostra o resultados.

QUADRO 1 - Pontos fortes e fracos da avaliação de desempenho

\begin{tabular}{|l|l|l|l|}
\hline Pontos fortes & $\%$ & Pontos fracos & $\%$ \\
\hline $\begin{array}{l}\text { Identificação da necessidade de } \\
\text { treinamento }\end{array}$ & $50 \%$ & $\begin{array}{l}\text { Erros no preenchimento do } \\
\text { formulário }\end{array}$ & $20 \%$ \\
\hline $\begin{array}{l}\text { Apoio em relação aos processos de } \\
\text { tomada de decisão administrativa }\end{array}$ & $10 \%$ & $\begin{array}{l}\text { Sentimento de injustiça por } \\
\text { alguns funcionários }\end{array}$ & $80 \%$ \\
\hline Feedback do trabalho & $40 \%$ & & \\
\hline
\end{tabular}


Fonte: Dados da pesquisa 2017

Saber identificar a necessidade de treinamento e o feedback no trabalho são vistos como pontos fortes na avaliação de desempenho; o sentimento de injustiça por alguns funcionários é visto como fraco na avaliação de desempenho. Saber reconhecer esses pontos pode "colaborar na determinação e no desenvolvimento de uma política adequada de RH às necessidades da organização" (CHIAVENATO, 2002, p. 326).

Os entrevistados também foram indagados sobre o fator motivação ao receber feedback de sua liderança, 60\% disseram que sim. Apesar de as ferramentas serem falhas e acontecerem as injustiças, eles conseguem perceber seus pontos fortes $e$ fracos para trabalhar buscando a melhoria. Quarenta por cento $(40 \%)$ responderam que não, pois as ferramentas são falhas, os líderes muitas vezes não sabem passar e monitorar os pontos a serem trabalhados.

Percebe-se, através dos questionários, que a avaliação de desempenho na Cooperativa precisa de melhorias, pois os líderes devem ser trabalhados e as ferramentas utilizadas de forma a trazer resultados mais práticos.

\subsection{QUESTIONÁRIO APLICADO A GESTÃO DE RECURSOS HUMANOS}

De acordo com o questionário aplicado para o gestor de pessoas, as ferramentas utilizadas para avaliar o desempenho dos funcionários são questionários para medir dados quantitativos, qualitativos e de desempenho. Com pontuação de 1 a 5 e somando um total de $100 \%$.

Quando foram perguntados como é aplicada a avaliação de desempenho, respondeu ser através de formulário que deverá ser preenchido pelo gestor e pelo funcionário, avaliação $180^{\circ}$. Após ambos avaliarem, o gestor de RH passa a avaliação para o funcionário e depois para a diretoria. A periodicidade é de 6 em 6 meses.

Ao ser interrogado sobre quais melhorias eles propõem sobre a avaliação de desempenho aplicada na empresa, o mesmo disse que realizar mais apresentações 
para divulgação da ferramenta e a forma de preenchimento dos formulários para todos na empresa. Também fazer com que a mesma tenha mais efetividade e resultado na prática, pois muitas vezes fica só no papel, falta um plano adequado para cada funcionário.

Foi questionado sobre quais são os pontos positivos e negativos da avaliação de desempenho. Dentre os pontos positivos, destacou: desenvolvimento pessoal e profissional, melhoria dos resultados organizacionais, necessidades de treinamento, apoiar processos de tomada de decisão administrativa, entre outros. Dentre os pontos negativos, relatou: necessidade de ajustes frequentes nos instrumentos de avaliação, ou não utilização dos resultados da avaliação na gestão organizacional, entre outros.

Interrogado sobre como é feito o acompanhamento das avaliações. O mesmo disse que é pela área de gestão de pessoas, que realiza o trabalho de divulgação e recebe os formulários dos avaliadores e avaliados.

Perguntou-se também se há um plano de desenvolvimento individual (PDI). A resposta foi positiva e explicou-se que é realizado através de um plano de melhoria que é elaborado e acompanhado pelo gestor do setor para cada funcionário que possui alguma competência a desenvolver e o funcionário é acompanhado de 1 em 1 mês.

Quando perguntado qual é o indicador para medir a eficácia da avaliação de desempenho o gestor de pessoas disse que não há, pois segundo os relatos acima a avaliação ainda é muito falha e precisa de melhorias.

A avaliação de desempenho, na Cooperativa, segue os padrões relatados por Chiavenato (2002), pois é o setor de recursos humanos o responsável pela avaliação de desempenho de todas as pessoas da organização. A comissão de avaliação é escolhida pela própria organização; é formada por pessoas de órgãos diversos, que participam de todas as avaliações para manter o equilíbrio dos julgamentos. 
A avaliação do desempenho, pelo exposto, possibilita, aos gestores e às organizações, a medição e a análise da performance de cada funcionário, motivandoos à promoção de carreira dentro da empresa.

\section{CONCLUSÃO}

A avaliação de desempenho deve traduzir a missão da empresa e contemplar outras perspectivas além da financeira tradicional, para que desta forma, possa garantir o sucesso dos negócios. Para o estudo deste tema em uma cooperativa de crédito foi levantada uma questão sobre quais as ferramentas utilizadas para avaliar o desempenho dos funcionários e como ela é aplicada. O questionamento foi respondido após o estudo bibliográfico e o estudo de caso.

As hipóteses estabelecidas foram confirmadas, pois inexiste um treinamento para as lideranças e colaboradores da Cooperativa de Crédito fazendo com que a avaliação de desempenho não gere resultados positivos; as ferramentas de avaliação podem conter falhas e não estarem de acordo com os objetivos da Cooperativa de Crédito e a forma de avaliar não está de acordo com os padrões da Cooperativa de Crédito e os responsáveis pela avaliação podem não ser as pessoas mais indicadas e preparadas.

Desse modo, foram alcançados tanto o objetivo geral quanto os objetivos específicos.

Após o estudo, percebeu-se que, na visão dos funcionários, estagiários e menores aprendizes a avaliação não é eficaz uma vez que não traz resultados práticos e o plano de desenvolvimento não é coerente, pois muitas não são monitoradas de forma correta; devido a isto a gestão de pessoas não consegue aplicar de forma correta a ferramenta e muitos gestores têm dúvidas na hora de passar o resultado; ocorrendo falhas nas ferramentas; assim há necessidade de treinamentos para os gestores aplicarem a avaliação de desempenho.

Na visão da gestão de recursos humanos, é preciso realizar mais apresentações para divulgação da ferramenta e a forma de preenchimento dos formulários para todos na 
empresa. Citou alguns pontos positivos da avaliação de desempenho, como desenvolvimento pessoal e profissional, melhoria dos resultados organizacionais, apoiar processos de tomada de decisão administrativa, entre outros. Dentre os pontos negativos, relatou: necessidade de ajustes frequentes nos instrumentos de avaliação ou não utilização dos resultados da avaliação na gestão organizacional, necessidade de treinamento, inexistência de um indicador para medir a eficácia da avaliação de desempenho.

Conclui-se que a avaliação de desempenho na Cooperativa de Crédito ainda é falha e precisa de melhorias. Propõe-se as seguintes sugestões: treinamentos para os gestores aplicarem de forma correta a avaliação, fazer ajustes nas ferramentas e instrumentos de avaliação, usar os resultados na gestão organizacional e criar um indicador para medir a eficácia da avaliação.

\section{REFERÊNCIAS}

CAMILO, Caio. O que é avaliação de desempenho e os tipos de avaliação. 2016. Disponível em: <http://www.empreendedorcurioso.com/single-post/2016/05/10>. Acesso em: 29 ago. 2017.

CHIAVENATO, Idalberto. Gestão de pessoas: o novo papel dos recursos humanos nas organizações. 4 ed. Barueri, São Paulo: Manole, 2014.

Recursos humanos. Ed. Compacta. 7 ed. São Paulo: Atlas,

2002.

Desempenho Humano nas Empresas: Como Desenhar Cargos e Avaliar o Desempenho - 4. Ed. - São Paulo: Atlas, 1998.

DAVIS, Keith. Comportamento Organizacional. São Paulo: Pioneira, 1992.

GIL, Antônio Carlos. Como elaborar projetos de pesquisa. 4. ed. - São Paulo: Atlas, 2002. 
Gestão de pessoas: enfoque nos papeis profissionais. São

Paulo: Atlas, 2001.

MARTINS, Vinícius Gomes, GIRÃO Luiz Felipe de Araújo Pontes, SILVA E FILHO Augusto Cézar da Cunha, ARAÚJO Aneide Oliveira. A utilização de modelos de avaliação de desempenho sob a perspectiva do Gecon e do Balanced Scorecard: Estudo de Caso em uma Central de Cooperativas de Crédito. 2013. Disponível em: <file://C:/Users/lupri/AppData/Local/Temp/16276-28884-2-PB.pdf>. Acesso em: 14/07/2017.

MOTTA, Carolina da Cruz. Avaliação de Desempenho. 2005. Brasília: Centro Universitário de Brasília, 2005.

PEREIRA, C. A. Ambiente, empresa, gestão e eficácia. In.: CATELLI, A. (Coord.). Controladoria. São Paulo: Atlas, 1999a. p. 35-78.

PINHEIRO, Marcos Antônio Henriques. Cooperativa de Crédito: História da Evolução Normativa no Brasil - 6 ed. - Brasília: BCB, 2008.

PONTES, B.R. Avaliação de Desempenho: Nova Abordagem - 7 ed. - São Paulo: DLTR, 1999.

SICOOB COPERMEC. Disponível em: <http://www.sicoobcopermec.com.br/Páginas /Institucional/defaut.as.px>. Acesso em: 14 jul. 2017.

VERGARA, Sylvia Constant. Projetos e Relatórios de Pesquisa em Administração. 3. ed. São Paulo: Ed. Atlas, 2000.

\section{ANEXOS}

Anexo 1 - Questionário aplicado aos funcionários da Cooperativa. Questionário 1 Funcionários.

Pesquisa Interna 
Prezado colaborador,

Esta pesquisa busca conhecer sua opinião sobre a avaliação de desempenho aplicada na empresa.

Contamos com seu auxílio.

A - Perfil do usuário:

1) Sexo

( ) Masculino ( ) Feminino

2) Idade

( ) De zero a 18 anos

( ) De 19 a 23 anos

( ) De 24 a 28 anos

( ) De 29 a 33 anos

( ) De 34 a 38 anos

( ) De 39 a 48 anos

( ) De 49 a 53 anos

( ) De 54 a 58 anos

( ) 59 anos ou mais

3) Grau de escolaridade

( ) Ensino Fundamental incompleto 
( ) Ensino Fundamental completo

( ) $2^{\circ}$ grau incompleto

( ) $2^{\circ}$ grau completo

( ) 3ograu incompleto

( ) 3o grau completo

( ) Pós graduação

( ) Mestrado

\section{Questionário 1 - Funcionário}

1) Como você percebe a eficácia (O resultado da Avaliação de Desempenho) que lhe é aplicada?

2) O resultado é positivo ou negativo?

3) Sua liderança imediata sabe passar corretamente sua Avaliação de Desempenho?

4) Como você avalia as ferramentas de Avaliação de Desempenho utilizadas pela Gestão de Pessoas da sua empresa?

5) Quais são os pontos fortes e fracos da Avaliação de Desempenho?

6) Vocês se sente motivado ao receber feedback de sua liderança?

\section{Anexo 2 - Questionário aplicado ao Gestor de Recursos Humanos}

\section{Questionário 2 - Gestão de Pessoas}

1) Quais são as ferramentas utilizadas para avaliar o desempenho dos funcionários da Empresa? 
2) Como é aplicada a Avaliação de Desempenho?

3) Quais as melhorias você propõe na Avaliação de desempenho?

4) Quais são os pontos positivos da Avaliação de Desempenho? E os negativos?

5) Como é feito o acompanhamento das Avaliações de Desempenho?

6) Há um PDI Plano de Desenvolvimento Individual. Se sim, como é feito?

7) Qual é indicado para medir a eficácia da Avaliação de Desempenho? Relate algum exemplo. 